\title{
O mito da autoestima na aprendizagem escolar
}

\author{
Adriana de Fátima Franco
}

\begin{abstract}
Resumo
Este artigo analisa, nos marcos da perspectiva sócio-histórica, a construção social da autoestima e suas relações com o fracasso escolar. Fundamentada nos pressupostos de Vigotski, nega a possibilidade da valoração que o sujeito faz de si estar atrelada a atributos naturalmente humanos e presentes desde o nascimento. A compreensão do ser humano é feita a partir de uma análise de homem enquanto ser concreto, social, histórico e cultural que constrói sua humanidade na interação com outros homens, na qual os processos psicológicos não são dados e sim produzidos. Apresenta uma análise crítica dos modelos teóricos que consideram a autoestima como um conceito fechado em si mesmo. Essa análise da autoestima no contexto escolar é fundamental se se pretende desmistificar esse conceito nas relações escolares.
\end{abstract}

Palavras-chave: Fracasso escolar, consciência, autoestima.

\section{The self-esteem myth and the school learning}

\begin{abstract}
This article analyzes the social construction of self-esteem and its relations to school failure from the socio-historical perspective. According to Vigotski's studies it is impossible to ascribe the concept that the individual makes of her/himself to natural human attributes existing from the day of her/his birth. The understanding of the human being is grounded on an analysis of man as a concrete, social, historical and cultural being who constructs her/his humanity in the interaction with other people. The psychological processes are not given, but acquired. We present a critical analysis of the theoretical models that consider self-esteem as a closed concept in itself. This analysis of self-esteem within the school context is fundamental when one wants to demystify some concepts in school relations.
\end{abstract}

Keywords: Academic failure, conscience, self-esteem.

\section{El mito de la autoestima en el aprendizaje escolar}

\section{Resumen}

Este artículo analiza en los marcos de la perspectiva socio-histórica la construcción social de la autoestima y sus relaciones con el fracaso escolar. Fundamentada en los postulados de Vigotski, niega la posibilidad de que la valoración que el sujeto hace de si esté ligada a atributos naturalmente humanos y presentes desde el nacimiento. La comprensión del ser humano es hecha a partir de un análisis del hombre como ser concreto, social, histórico y cultural que construye su humanidad en la interacción con otros hombres donde los procesos psicológicos no son dados y, sí, producidos. Presenta un análisis crítico de los modelos teóricos que consideran a la autoestima como un concepto cerrado en sí mismo. Ese análisis de la autoestima en el contexto escolar es fundamental si se pretende desmitificar ese concepto en las relaciones escolares.

Palabras-clave: Fracaso escolar, conciencia, auto-estima. 


\section{Introdução}

Este artigo analisa, nos marcos da perspectiva sóciohistórica, a construção da autoestima, apontando para a produção social da subjetividade humana. Ancorada nos pressupostos de Vigotski, a presente análise nega toda e qualquer possibilidade da valoração que o sujeito faz de si estar atrelada a atributos naturalmente humanos e presentes desde o nascimento. Entendemos o ser humano como singular, concreto, social e histórico.

A Psicologia fundamentou a questão do fenômeno psicológico à luz de diferentes modelos teóricos. Segundo Smolka (2004), são comuns, nessa área do conhecimento, explicações com base em uma concepção de homem que o vê como ser abstrato, absoluto e universal. Estas são abordagens de cunho idealista e mecanicista, enfoques que trabalham com a noção da existência de uma natureza humana comum a todos os homens. Nesta concepção, o homem é visto como tendo uma essência predeterminada, algo que the é dado pelo pertencimento à espécie. Contrapondo-se a essas ideias, a perspectiva sócio-histórica entende o homem como ser sócio-histórico, isto é, crê que o homem seja um ser concreto, social, histórico e cultural que constrói sua humanidade na interação com outros homens, na qual os processos psicológicos não são dados e sim construídos nesta rede.

Para que não haja qualquer dúvida a respeito de nossa posição teórica, pelo fato do termo autoestima estar ligado a um arcabouço teórico idealista, inicialmente definimos autoestima tal qual a entendemos. Assim, acreditamos que, desde o nascimento, o homem encontra-se cercado por atribuições de valores positivos e negativos; a autoestima é, então, vista enquanto uma valoração que o sujeito faz do que ele é, sendo construída nas relações que mantém com o mundo. Desta forma, a autoestima não é natural, dada ou inata ao homem. Ela é algo tênue, que surge das diferentes formas pelas quais significamos as situações vividas ao longo da vida, ou seja, se prevalecentemente de modo positivo ou negativo, ainda que as significações, em muitos casos, sejam contraditórias e nem sempre claras. De qualquer maneira, a tendência positiva ou negativa, se recorrente, tende a se estabilizar. Se, por outro lado, a vida oferece novas circunstâncias, nas quais tais significações podem ser modificadas, a consciência de si pode sofrer alterações de vulto, imprimindo novas marcas. Isto ocorre também no que se refere à apreensão que fazemos acerca de nossa capacidade de aprender. Muitas são as pesquisas (Machado, 1997; M. A. A. Moysés, 2001; Patto, 1996) que apontam para o enorme contingente de sujeitos que passaram por experiências negativas, por práticas escolares nefastas. Acreditamos que essas experiências, muitas vezes, marcaram de tal forma o sujeito que fica difícil para a pessoa ressignificar sua história, mesmo diante de novas circunstâncias. Esbarra-se em algo que já faz parte do sujeito, que não é de sua natureza: algo que foi nele construído ao longo das circunstâncias de sua própria vida.

\section{A questão da autoestima em diferentes contextos}

Em quais cenários se encontram os estudos acerca da autoestima? Como o tema vem sendo entendido e com quais finalidades vem sendo empregado? Quais são as discussões realizadas? Para esclarecer estas indagações, buscamos delinear o contexto no qual a autoestima se encontra inserida. De fato, a questão da autoestima é comumente abordada por modelos teóricos que a consideram como um conceito fechado em si mesmo, ou seja, como a representação de algo que é próprio do indivíduo. Estas explicações fundamentam-se em modelos explicativos essencialmente idealistas que, segundo Martins (2001), não avançam em direção a uma efetiva compreensão da dimensão psicológica dos seres humanos:

o grande problema dessas abordagens reside no fato de que ao se debruçarem sobre seu objeto o tomam em separado da totalidade histórico-social que o sustenta. Ao perder sua sustentação, perdem-se as possibilidades de aprendê-lo em sua concretude, substituindo-se esta apreensão por outras, abstratas e vazias (pp. 8-9).

No contexto escolar, a visão idealista também impera nas análises realizadas por professores e psicólogos. Poli (2003) acredita que, para justificar as explicações sobre o fracasso escolar das crianças de classes trabalhadoras, a escola contou com o auxílio da psicologia positivista, cuja tarefa centra-se na descrição empírica do sujeito da aprendizagem. Para essa autora, tal descrição, "seguindo os princípios do pensamento positivista, adquire um caráter de universalidade, valendo para toda e qualquer realidade social e cultural" (p. 28).

Os estudos sobre autoestima, assim como qualquer outro tema, não podem ser tomados de maneira recortada em relação aos seus fundamentos. Não podemos ignorar que, muitas vezes, nos deparamos com o uso da autoestima para se referir a características inerentes ao sujeito. Neste sentido, há uma concepção de ser humano na qual sua singularidade decorre de sua essência - qualidades próprias e inalienáveis - que independem das condições em que vive e se desenvolve.

Segundo Tavares (2002), a expressão autoestima, além de trazer implícito o sentido de sucesso e de ser capaz, também traz em seu bojo a visão de um indivíduo que se ajusta às constantes mudanças da realidade. Criticamente, essa autora afirma que o senso comum considera que a autoestima: "é definida, assim, como visão positiva incontestável de si mesmo, [de modo que] acreditar nas possibilidades pessoais é parte das condições do sucesso escolar, sem considerar o contexto e outras dificuldades que possibilitam e dificultam o rendimento escolar" (p. 4).

Ainda segundo Tavares (2002), existe uma vasta bibliografia americana apropriada por programas sociais brasileiros com o objetivo de desenvolver práticas que promovam a autoestima de alunos na escola. A autoestima é, assim, vista como um fator desvinculado do contexto em que vive o sujeito. O que seria trabalhar com a autoestima 
"negativa" de um aluno, senão promover a aprendizagem? Concordamos com a autora que, em muitos momentos, encontramos o termo sendo utilizado na perspectiva citada acima; porém discordamos que isto seja inerente ao próprio tema. Acreditamos que o problema reside em algo maior, ou seja, decorre da visão de homem e de mundo que norteia estas discussões. Para tanto, recorremos à literatura disponível.

Verificamos que um ponto constante nos estudos acerca da autoestima e do autoconceito, mesmo em momentos em que o social é apontado, é a visão de que ambos são traços do sujeito. É possível dizer que esses estudos podem, na melhor das hipóteses, descrever, de forma "congelada", características acerca da autoestima, mas não dão conta de todo o processo inerente a sua construção no conjunto das relações sociais em que está inserido.

$\mathrm{Na}$ análise desses estudos, consideramos que o método utilizado e os resultados apontam para a avaliação de um homem em contexto abstrato, no qual estratégias visando produzir e/ou transformar a autoestima dos sujeitos participantes são apresentadas, sem que haja, como objetivo, analisar a constituição do sujeito. Busca-se, antes, medir, testar, comparar e descrever as respostas apresentadas nos questionários. Neste sentido, os estudos de Barroso e Barreto (1976), L. M. M. Moysés (1982), Silva e Alencar (1986) podem ser apontados.

Ainda que o social seja citado em alguns desses estudos como fator relevante, a interpretação que se faz dele não é adequada, pois a análise é permeada por dicotomias: interno/externo, dentro/fora e social/individual. Partimos do pressuposto de que estas dicotomias são falsas e, portanto, não devem ser apresentadas mecanicamente, de forma separada. Na realidade, entendemos que estes aspectos constituem uma unidade. E, ainda, que o humano não deve ser nem compartimentado nem tomado com um ser que possui, intrinsecamente, uma essência que lhe determina certas características básicas, inelutáveis. Antes, o ser humano é constituído - e constituinte - do processo histórico e social.

Precisamos realizar uma análise crítica acerca dos resultados das pesquisas. Medir, classificar e comparar a autoestima de diferentes grupos implica transformação da realidade? Não estaríamos deixando de lado alguns fatores chaves da exclusão escolar? Que outras determinações estão envolvidas nesse fenômeno? Será que não estamos, na tentativa de romper com o fracasso escolar, apenas reafirmando que a capacidade ou incapacidade do sujeito em aprender reside em si mesmo, como nos quer fazer crer a ideologia de muitos?

A análise da construção da autoestima deve, necessariamente, incluir as relações reais e o contexto histórico e social do sujeito. Estudos mais recentes (Oliveira, 1994; Santos, 2003) caminharam nesta direção e passaram a discutir questões que envolvem o papel do outro na constituição do sujeito. Para Santos (2003), a autoestima constrói-se na relação com os demais membros da cultura, uma vez que contextos socioeconômicos, culturais, familiares e escolares exercem variadas influências na trama de interações que são, de acordo com a teoria sócio-histórica, constitutivas do indivíduo.

Sendo assim, a autoestima é um fenômeno mais social e sua construção e transformação parecem estar diretamente vinculadas à qualidade das relações estabelecidas pelo sujeito ao longo da vida.

A relação entre autoestima e aprendizagem também não é recente e passou por vários momentos. Entre eles, podemos destacar três. O primeiro deles encontra-se relacionado às ideias ligadas ao Movimento da Escola Nova, bem como à criação dos cursos de Orientação Educacional e à implantação do Serviço de Orientação Educacional nas escolas (Oliveira, 1994). Cabe aqui uma reflexão acerca destes movimentos, gerados em função das críticas feitas à pedagogia tradicional, que salienta o poder da escola em desempenhar a função de equalização social. Segundo essa visão, o indivíduo sente-se integrado quando é aceito pelo grupo. Para Saviani (1995), o movimento escolanovista deslocou o foco da questão pedagógica do intelecto para o sentimento, do aspecto lógico para o psicológico. Os educadores voltaram seus interesses para o desenvolvimento afetivo e para o ajustamento psicológico e social do aluno, prevalecendo análises estritamente psicológicas.

Temos uma visão "romântica", que leva as pessoas a imaginarem ser possível criar um apreço por si mesmas, independente das condições concretas em que vivem. Nesta visão, podemos citar, também, as promessas feitas pela literatura de autoajuda, ou seja, como fazer para alcançar "o paraíso interior".

De outro lado, temos a visão tecnicista, na qual se postula que o reforçamento positivo produz uma autoestima positiva, mesmo em condições precárias de ensinoaprendizagem. Essa pedagogia busca tornar o processo educativo mais objetivo e operacional, a despeito de suas mazelas. Postula, assim, que cabe à educação proporcionar aos alunos um eficiente treinamento para a execução das múltiplas tarefas demandadas, continuamente, pelo sistema social (Saviani, 1995).

O segundo momento surge com as ideias que vinculavam uma visão crítica da escola e de suas funções na sociedade capitalista. Segundo Saviani (1995, p. 27), tais teorias acreditam: "não ser possível compreender a educação senão a partir dos seus condicionantes sociais. Entretanto, [...] na análise que desenvolvem, chegam invariavelmente à conclusão de que a função própria da educação consiste na reprodução da sociedade em que ela se insere".

As discussões voltaram-se, então, quase que exclusivamente para o processo de produção social do fracasso escolar, perdendo-se, com isso, a dimensão psicológica, ou seja, aquela própria dos sujeitos. Este é o motivo pelo qual, durante a década de 1980, raros são os trabalhos publicados a esse respeito no Brasil.

O terceiro período é mais recente. Nos últimos anos, alguns autores - embora de diferentes formas - vêm se ocupando em debater o assunto buscando resgatar 
questões psicológicas (que dizem respeito ao sujeito), sem deixar de lado a contextualização histórica do fenômeno (Amaral, 2001; Oliveira, 1994; Santos, 2003).

Esses estudos apontam que a dimensão emocional é fator imprescindível para a "tomada" de consciência e para a ação do sujeito em seu mundo social. Na medida em que os alunos percebem-se como capazes de aprender, as relações mantidas com a professora e com o grupo são modificadas.

Com o objetivo de investigar a constituição social e histórica do autoconceito de alunas com traços de negritude (e consideradas "pretas" pelos colegas), Oliveira (1994) chamanos a atenção para o fato de que existe um jogo de sentidos que permeia as interlocuções produzidas entre os alunos.

Ao escrever sobre o tema "constituição da imagem de si", trabalhando com dados de um grupo de crianças que frequentava a classe de aceleração, Amaral (2001) apontanos que, para aqueles com um histórico de reprovação escolar, esse fato não é encarado como mais um episódio em sua vida, mas sim como traço da imagem que apresentam ao interlocutor. Pode-se dizer que, para as crianças estudadas, a história de fracasso ocupa maior destaque do que possíveis situações de sucesso vividas no presente. A marca do fracasso parece, pois, ser dominante. Os textos dos alunos trazem informações dessa ordem: "moro com meus pais, brinco com meus amigos e já fui reprovado". Segundo a autora, é possível concluir que a criança tem consciência do insucesso e que, neste contexto, a reprovação é um traço marcante da imagem que a criança constrói de "si". Desta forma, os resultados escolares assumem aí um papel fundamental, em especial no que diz respeito à sua atuação no espaço escolar.

Ao analisar a questão da autoestima e do autoconceito de professores por meio de relatos autobiográficos, entrevistas e dinâmicas de grupo, Santos (2003) aponta-nos que esses processos são frutos de uma constituição social e histórica. A autora discute que um bom professor não necessariamente tem - ou precisa ter - autoestima elevada, uma vez que este não é o único ingrediente necessário ao bom exercício profissional. Considera, porém, que este é um aspecto relevante, dado que pessoas com percepção positiva de suas qualidades tendem a se envolver em seus afazeres com confiança, alcançando, assim, maiores chances de obter sucesso.

Para finalizar, trouxemos os estudos de Petrovski (1989), nos quais o autor nos apresenta uma interessante discussão sobre o desenvolvimento da personalidade e ressalta um aspecto importante dela: a autoavaliação.

Com a finalidade de objetivar a compreensão, apresentamos os conceitos de imagem do ego e autoavaliação. Sobre o primeiro, o autor nos diz:

a imagem do "ego" é um sistema relativamente estável, que se encontra relativamente conscientizado. É percebido como um sistema único de noções do individuo sobre si próprio, na base do qual ele organiza a sua interação com os outros [...]. Desta maneira, a imagem do "ego" inscreve-se na estrutura da personalidade, passando a ser uma orientação em relação a si próprio. (Petrovsky, 1989, p. 259)
O autor ressalta que esta formação é dinâmica e construída nas relações sociais, podendo mudar ao longo da vida. A "imagem do ego" seria, ao mesmo tempo, o "ego" ideal do sujeito - aquilo que ele deve ser para corresponder às exigências das outras pessoas. Já ao tratar da avaliação que a pessoa faz acerca de si, o mesmo autor apresenta o conceito de autoavaliação, definido como "a avaliação de si própria, de suas possibilidades e de seu lugar entre as pessoas" (Petrovski, 1989, p. 259).

Nesse momento, parece ser importante retomar os caminhos e descaminhos trilhados pela autoestima e aprendizagem até o presente momento. Destacamos, assim, algumas análises: a) as estritamente psicológicas; b) as que pautam a discussão, quase que exclusivamente, no plano sociológico; c) as atuais, que discutem o fato da produção do fracasso produzir, também, baixa autoestima que, por sua vez, mantém o fracasso escolar. Pensamos, portanto, que se a autoestima influencia a aprendizagem escolar, esta também incide sobre a autoestima e ambas são construídas na relação com o outro.

Falta-nos uma discussão sobre como se forma a consciência - e, mais especificamente, a consciência de si. De igual modo, não contamos com uma discussão sólida acerca de como essa "consciência de si" é valorizada (algo que chamamos aqui de autoestima), assumindo aspectos positivos ou negativos e influenciando a motivação para ação. Ainda, não sabemos como tudo isso se apresenta no contexto escolar.

\section{A construção da consciência na perspectiva sócio-histórica}

$\mathrm{Na}$ vertente sócio-histórica, diferentes autores discutem a questão da construção da consciência. Para Leontiev (1978), ela é a expressão de uma forma superior de psiquismo, que surge em consequência da transformação evolutiva. Neste processo de transformação, agem de maneira decisiva o trabalho e o desenvolvimento da linguagem. Já Aguiar (2000) considera que a consciência constitui a forma como o indivíduo apreende o mundo físico e social. Essa apreensão, por sua vez, parece ser a base da constituição do sujeito, fruto de um processo de desenvolvimento profundamente enraizado nas ligações entre história individual e história social. Martins (2001), por sua vez, define consciência enquanto: "um sistema de conhecimentos que vai se formando no homem à medida que este vai apreendendo a realidade, pondo em relação as suas impressões diretas com os significados elaborados e veiculados pela linguagem, expressando as primeiras através das segundas." (p. 86).

Segundo a autora, se a consciência é social por natureza, não cabe estabelecer uma distinção entre a dimensão social e individual da consciência.

De fato, tendo em vista que as condições de vida social não esgotam as possibilidades de existência dos indivíduos, não pode existir uma coincidência automática entre as dimensões social e individual da consciência. 
Analisando as definições dos diferentes autores, podemos concluir que a consciência pode ser compreendida enquanto apropriação dos atos vivenciados pelo indivíduo, nas relações com outros indivíduos e com o mundo. Daí a importância da linguagem. Como essa apropriação se dá por meio de signos, pode-se dizer que a estrutura da consciência é sígnica ou, melhor dizendo, ela é semioticamente estruturada. Esse aspecto foi bastante salientado por Vigotski (1987) quando afirmava que a dimensão sígnica perpassa a elaboração da consciência. Para esse autor, é por meio das palavras que o pensamento passa a existir: "o pensamento não é simplesmente expresso em palavras; é por meio delas que ele passa a existir" (p. 108).

Consideramos de fundamental importância ressaltar que a atividade partilhada é responsável por produzir significações que, ao serem apropriadas, criam o plano do sujeito, ou seja, sua consciência. Desta forma, a consciência surgirá não só mediante a internalização dos signos, mas por meio do processo de significação, que traduz as condições de funcionamento da sociedade, suas estruturas de relação e suas práticas sociais (Neves, 1997).

Para Pino (1999), a significação tem o poder de converter um fato natural em fato cultural e, assim, permitir a passagem do plano social para o plano individual. A própria natureza da significação faz dela algo que pode ser partilhada por todos, que é de todos e de ninguém em particular, na medida em que incorpora a singularidade de cada um dos que a compartilham.

Segundo Rosseti-Ferreira, Amorin e Silva (2004), o ser humano constrói-se na relação com o outro e com o mundo, necessitando do espaço relacional para se diferenciar e se assemelhar:

as características pessoais são construídas na história interacional de cada um e tomam sentido em relações situadas e contextualizadas. O outro se constitui e se define por mim e pelo outro, ao mesmo tempo em que eu me constituo e me defino com e pelo outro. É nesse interjogo que se dá o processo de construção das identidades pessoais e grupais, ao longo de toda vida da pessoa (p. 25).

Temos, portanto, um indivíduo real que "se revela enquanto síntese de um sistema de relações sociais e, ao mesmo tempo, enquanto sujeito destas relações" (Martins, 2001 , p. 9). Nessa medida, podemos considerar que a consciência reflete o mundo objetivo, ou seja, é a construção, no nível subjetivo, da realidade objetiva. É formada no trabalho e nas relações sociais entre os homens ao produzir os meios necessários à vida. A consciência permite ao homem conhecer e avaliar tanto o mundo físico e social como a si mesmo. A esse último aspecto - a valoração de si mesmo - chamamos de autoestima.

Ao conceber o homem, entendendo-o como um ser eminentemente social, Vigotski (1987) estabelece que a formação e o desenvolvimento do psiquismo humano ocorrem com base em uma crescente apropriação dos modos de pensar, sentir e agir culturalmente elaborados. Nesse sentido, a perspectiva sócio-histórica considera que o homem não possui uma natureza humana inata e imutável. Ao contrário, segundo essa visão, ele conta tão somente com uma "condição humana", uma vez que constrói sua existência na e pelas interações mantidas com a realidade física e social, buscando satisfazer suas necessidades.

Como afirma Leontiev (1978), o homem, ao nascer, é candidato à humanidade e é introduzido no mundo da cultura por outros indivíduos; segundo ele, o homem é um ser de natureza social, tudo o que há de humano nele provém da sua vida em sociedade, no seio da cultura criada pela humanidade: "cada indivíduo aprende a ser um homem. O que a Natureza lhe dá quando nasce não basta para viver em sociedade. É-lhe ainda preciso adquirir o que foi alcançado no decurso do desenvolvimento histórico da sociedade humana" (p. 267).

Em outro momento, o mesmo autor acrescenta: "o homem possui ao nascer uma aptidão que apenas o distingue fundamentalmente dos seus antepassados animais - a aptidão para formar aptidões especificamente humanas" (Leontiev, 1978, p. 273). Tudo isso implica que a apropriação da cultura - que humaniza o bebê humano - só é possível a partir do contato social. Neste processo, a criança vai tornando seu aquilo que é patrimônio de seu grupo cultural, atribuindo-Ihe sentidos a partir daqueles já construídos em sua história de interações.

Segundo Martins (2001, p. 85): "a formação do ser humano representa um processo que sintetiza o conjunto de fenômenos produzidos pela história humana, de tal forma que a construção do indivíduo se situa no cerne de uma construção mais ampla: a da humanidade".

O contexto interativo, com suas significações, chama a atenção para o fato de que existe uma relação dialética que envolve o individual e o social no desenvolvimento humano. Vigotski postula, assim, uma noção de sujeito que não é mera réplica do meio ambiente, nem alguém pré-formado, mas um ser que constrói, na e pela interação, o contexto sócio-histórico do qual faz parte, sendo, simultaneamente, por ele constituído. Dessa forma, podemos afirmar que: "homem e sociedade vivem, portanto, uma relação de mediação, em que cada polo expressa e contém o outro, sem que nenhum deles se dilua no outro ou perca a sua singularidade" (Aguiar, 2000, p. 127).

De acordo com Davis e Espósito (1989), a interação social só pode ser compreendida no campo das relações que se estabelecem entre indivíduos reais e concretos, num determinado tempo e lugar. Desta forma, atividades partilhadas, que se constituem na própria interação social, acabam por adquirir diferentes sentidos, a depender da forma como se desenvolve a história individual de cada parceiro no seio da estrutura social.

Assim sendo, nossa tarefa consiste em compreender esse indivíduo em sua singularidade. A compreensão da singularidade do sujeito reside, em última instância, na apreensão do processo particular pelo qual se dá a construção da consciência. Para Vigotski (1993), a psicologia deveria possibilitar a descrição e a explicação das funções psicológicas superiores, tais como a vontade, o pensamento, a linguagem e a consciência. Segundo o autor, o sujeito é 
um "destilado" das formas de relação mantidas com o real, concebendo o psiquismo sobretudo como um conjunto de funções de natureza cultural.

Para ele, as funções psicológicas superiores - que caracterizam o sujeito humano - surgem na e da interação com o ambiente sociocultural ao qual pertence. Ao assumir as relações sociais como definidoras do desenvolvimento das funções psicológicas superiores, o autor desloca definitivamente o foco da análise psicológica do campo do biológico para o campo da cultura. Não nega, entretanto, que a base material para o desenvolvimento de tais funções seja o cérebro (Vigotski, 1993).

Esse reconhecimento só ressalta a sua visão de homem enquanto ser formado pela interação de múltiplos fatores: biológico, social e psicológico. O outro assume, assim, papel fundamental na constituição do sujeito, em razão justamente de ser por meio de sua mediação que se torna possível a construção do psiquismo. Mas o outro não é tido como um simples mediador instrumental, uma vez que a mediação que exerce tem um sentido mais profundo: é condição de desenvolvimento (Sirgado, 2000).

O termo função parece caracterizar o psiquismo como algo em constante movimento, como bem aponta Sirgado: "o caráter vago do termo 'função', tal como é usado por Vigotski, coloca certas dificuldades conceituais, mas, por outro lado, ajuda a conceber o psiquismo como algo dinâmico, que está sempre se (re)fazendo e em perpétuo movimento" (2000, p. 70). Na obra Pensamento e Linguagem (1987), Vigotski estabelece que o desenvolvimento do psiquismo humano se dá com base em uma crescente apropriação dos modos de ação culturalmente elaborados. Desta forma, é o contato social que propicia gradualmente o processo de internalização.

Entendemos que, para Vigotski, o termo internalização é utilizado para demonstrar a reconstrução, no plano intrapsíquico, das funções existentes no plano interpsíquico. Temos que a atividade internalizada (cuja origem é material) é a atividade significada e não a atividade em si. Desse modo, a conversão do social em pessoal é um processo semiótico. Ficaria difícil entender, caso assim não o fosse, como essas funções operam de maneira diversa de pessoa para pessoa. Ainda sobre o tema, Sirgado afirma que:

é a significação que confere ao social sua condição humana, fazendo da sociabilidade animal - expressão de uma organização natural da convivência de indivíduos de uma mesma espécie - uma sociabilidade humana, expressão da maneira como os membros da espécie humana organizam a sua convivência. Isto quer dizer que a convivência humana é regida por leis históricas e não por mecanismos naturais ou biológicos (2000, p. 61).

Segundo o autor, o evento determinante da história humana é a criação dos mediadores semióticos que operam nas relações dos homens com o mundo físico e social. Esses mediadores transformam os sistemas de sinalização natural em espaços representacionais, fazendo surgir um mundo novo: o mundo simbólico ou da significação. A linguagem aparece, portanto, como ferramenta fundamental no processo de mediação das relações sociais, no qual o homem se constitui.

Desta forma, o autor trabalha a noção de que a constituição do sujeito pelo outro se dá no campo da intersubjetividade, entendida como: "o lugar do encontro, do confronto e da negociação dos mundos de significação privados (ou seja, de cada interlocutor) à procura de um espaço comum de entendimento e de produção de sentido, mundo público de significação" (Pino, 1999, p. 22).

O outro, nesta ótica, não é apenas um mediador instrumental: ele tem um sentido mais profundo, pois é condição de desenvolvimento.

Assim,

a consciência surgirá não só mediante a encarnação dos signos mas, também, por intermédio do processo de significação, que traduz as condições de funcionamento da sociedade, suas estruturas de relação e suas práticas sociais. Mas a consciência pertence, também, a um sistema com leis específicas, que é o sistema psíquico (Aguiar, 2000, p.133).

Vemos, então, que, para compreendermos a construção social da consciência, o pensar, agir e sentir só podem ser vistos de maneira integrada. Nesta direção, González Rey diz que:

o sentido é uma síntese subjetiva de dimensões culturais e sociais, históricas e atuais, que estão implicadas nas diversas opções do sujeito em cada momento concreto da vida. O sentido é sempre o resultado de um processo de subjetivação associado a um contexto concreto e imerso no sistema de sentidos subjetivos que caracteriza a vida atual do sujeito. O corpo nunca está separado da produção da trama complexa de sentidos associados com a existência do sujeito concreto dentro de um espaço culturalmente definido $(2004$, p. 61$)$.

Ao discutir o papel do signo nas conexões cerebrais, Vigotski mostra-nos que as funções psicológicas superiores são também produto de intensa atividade cerebral e afirma:

A psique não deve ser considerada como uma série de processos especiais que ocorre em algum lugar acima e à parte dos processos cerebrais, senão como expressão subjetiva deles mesmos (os processos), como uma característica especial das funções superiores do cérebro (1991, p. 100).

Nessa medida, temos que as funções psicológicas superiores são resultados da atividade humana, cuja base material é o cérebro. Podemos dizer que são as interações, que se manifestam como ações partilhadas e significadas, que permitem a formação de um plano interno - subjetivo - do sujeito. Mas, como esse sujeito não é passivo na interação, ele, a despeito dela, a internaliza de forma particular.

Ao nos embasar nos pressupostos da teoria sóciohistórica, percebemos que tanto a consciência como a autoestima são ambas construídas nas e pelas interações sociais, por meio da internalização das significações 
vinculadas nos contextos interativos. Mas como estes conceitos se articulam entre si? Quais são seus contornos e limites? O que abrange cada um deles?

Ora, entendemos que a construção do psiquismo humano é processual, algo que se dá na e pela atividade, em um determinado contexto social. Martins (2004a), ao discutir as ideias de Leontiev, afirma que:

com a divisão social do trabalho as relações entre significado e sentido pessoal não necessariamente são coincidentes, observação fundamental no estudo da personalidade. A ruptura entre significados e sentido pessoal determina uma mudança na estrutura interna da consciência própria da sociedade de classes desenvolvida. Nela o trabalhador aparta-se do seu próprio trabalho e a sua atividade vai deixando de ser para ele o que ela é de fato. Por esse processo, pode ir se estabelecendo uma absoluta discordância entre o resultado objetivo da atividade e o seu motivo, acompanhada consequentemente do descompasso entre seu conteúdo objetivo e seu conteúdo subjetivo, descaracterizador dos mais elementares sentimentos humanos. Esta ruptura se traduz psicologicamente na desintegração da unidade da consciência, outrora garantida pela oportunidade entre significados sociais e sentido pessoal, dando origem ao aparecimento de uma relação de alienação entre eles (p. 89).

Em outro momento, a autora aponta que a compreensão de si demanda o confronto mediado pela consciência entre atividades e motivos. Sem ele, não the parece possível organizar a atividade em torno de motivos vitais, de modo que a vivência humana aparece de maneira fragmentada.

\section{Considerações Finais}

Partimos da afirmação de que a atividade partilhada constitui o psiquismo. De fato, isso parece ocorrer em função de ser a interação social (que envolve atividade e comunicação) que nos permite construir conhecimentos sobre o mundo físico e social (inclusive sobre nós mesmos) e ocasião para valorá-los (em especial os que temos acerca de nós mesmos - a autoestima). A valoração pode, claro, ter sido construída sob condições de alienação e cristalizar o psiquismo em formas arcaicas, que aparecem para o próprio sujeito como imutáveis e independentes de sua ação. Se as novas informações não abalam o psiquismo, não há, como resultado, a produção de novas formas de ser, de pensar e de sentir. A consciência não se amplia. Por outro lado, se a realidade é multideterminada, cabe também pensar que mudanças na atividade partilhada podem promover novas significações, novas valorações e, consequentemente, novas formas de sentir, pensar e agir. O psiquismo, nesse caso, transforma-se e uma consciência diferente surge.

Temos clareza de que o cotidiano escolar de crianças que vivem histórias de fracasso é construído por uma multiplicidade de fatores. Neste sentido, a questão da autoestima está atrelada a um contexto amplo, que certamente carece de mudanças substanciais. Enquanto as condições concretas de vida não forem alteradas, alterações de vulto na consciência e, portanto, na forma de se avaliar não devem ser esperadas. Na verdade, crianças e jovens que vivenciam situações de não aprendizagem no contexto escolar precisam de condições de vida que permitam a formação de um pensamento mais organizado e melhor estruturado, em que significados e sentidos não sejam tomados de forma fragmentada. Falar em autoestima sem considerar a rede de relações em que o sujeito se constitui é como semear ao vento.

Segundo Poli (2003), discutir a questão da autoestima passa necessariamente pela proposta de um projeto político pedagógico que permita a promoção de princípios de solidariedade e identidade de classe. Não é possível transformar a autoestima fora de sua trama social. Mas não só isso. Tal como vemos, a escola é um locus importante de humanização, ou seja, de construção da consciência, tanto em seus aspectos cognitivos (apropriação crítica de conteúdos e operações) como afetivos e éticos. Nesse sentido, precisamos mesmo lutar por uma escola melhor se quisermos formar cidadãos com possibilidade de voar mais alto e de delinear um futuro passível de ser realizado. Sabemos, agora melhor do que nunca, que a autoestima não pode ser produzida, fabricada ou mudada como apregoam certas pedagogias idealistas. Ela depende, em sua maior parte, das condições de vida dos sujeitos e, nesse sentido, de uma escola de qualidade.

Se não for tomada por este prisma, a autoestima seria mais um fetiche, entendido como uma poção mágica que, se bem administrada, resolveria as mazelas da educação (Duarte, 2004). Entretanto, parece-nos inegável que a constituição do sujeito - de sua consciência - passa pela avaliação que ele faz de si mesmo. Esta avaliação acaba por influenciar a forma como esse sujeito irá agir, sentir e pensar o mundo e vice-versa. Temos aqui uma relação dialética, ou seja, ao mesmo tempo em que, na interação com os outros, se avalia e se objetiva no mundo, se é avaliado. Com isso, há necessariamente uma valoração, cujo significado pode ser internalizado.

A construção de uma imagem positiva de si enquanto aluno não é a única forma de se avaliar, nem abarca todas as dimensões da imagem que se faz de si. Porém, como bem nos lembra Martins (2004b), a educação é imprescindível para o desenvolvimento humano. Ela não só constitui uma das condições por meio das quais o ser humano adquire seus atributos fundamentais ao longo do processo históricosocial, como possibilita o desenvolvimento das funções psicológicas superiores, tipicamente humanas. Sendo assim, tudo indica que, na constituição do sujeito, esse é um espaço fundamental.

Segundo Saviani (2004), existe uma relação dialética entre educação e sociedade, ou seja, a educação é determinada pelos condicionantes sociais, mas tem um papel fundamental de transformação da sociedade. É justamente nesta contradição que temos a oportunidade de trabalharmos para a formação de sujeitos mais críticos, que se apropriam de seus determinantes para, desta forma, transformá-los. 
Acreditamos que essa é a mediação que a educação deve exercer: formar indivíduos capazes de perceber o real e de superar a realidade.

\section{Referências}

Aguiar, W. M. J. (2000). Reflexões a partir da psicologia sóciohistórica sobre a categoria - consciência. Cadernos de Pesquisa, $110,125-42$.

Amaral, S. A. (2001). A imagem de si em crianças com histórico de fracasso escolar à luz da teoria de Henri Wallon. Tese de Doutorado, Pontifícia Universidade Católica de São Paulo, São Paulo.

Barroso, C. L. de M., \& Barreto, E. S. S. (1976). O vestibular e a auto-estima do jovem. Cadernos de Pesquisa, 16, 48-61.

Davis, C., \& Espósito, Y. (1989). Papel e valor das interações sociais em sala de aula. Cadernos de Pesquisa, 71, 49-54.

Duarte, N. (2004). O bezerro de ouro, o fetichismo da mercadoria e o fetichismo da individualidade. Em N. Duarte (Org.), Crítica ao fetichismo da individualidade (pp. 1-21). Campinas, SP: Autores Associados.

Gonzáles Rey, F. (2004). Sobre a rede de significações, o sentido e a pessoa: uma reflexão para o debate. Em M. C. Rossetti-Ferreira, K. de S. Amorim, A. P. S. Silva (Orgs.), Rede de significações e o estudo do desenvolvimento humano (pp.59-65). Porto Alegre: Artmed.

Leontiev, A. (1978). O desenvolvimento do psiquismo (M. D. Duarte, Trad.). Lisboa: Livros Horizonte.

Machado, A. M. (1997). Avaliação e fracasso: a produção coletiva do fracasso escolar. Em J. G. Aquino (Coord.). Erro e fracasso na escola: alternativas teóricas e práticas (pp. 73-90). São Paulo: Summus.

Martins, L. M. (2001). Análise sócio-histórica do processo de personalização de professores. Tese de doutorado, Universidade Estadual Paulista, Marília, São Paulo.

Martins, L. M. (2004a) A natureza histórico-social da personalidade. Caderno Cedes, 62, 82-99.

Martins, L. M. (2004b). Da formação humana em Marx à Critica da Pedagogia das Competências. Em N. Duarte (Org.), Crítica ao fetichismo da individualidade (pp.53-63). Campinas, SP: Autores Associados.

Moysés, L. M. M. (1982). Efeitos da valorização pessoal e clarificação de valores sobre a auto-estima de menores institucionalizados. Tese de Doutorado, Pontifícia Universidade Católica do Rio de janeiro, Rio de Janeiro.

Moysés, M. A. A. (2001). A institucionalização invisível: crianças que não aprendem na escola. Campinas, SP: Mercado de Letras.

Neves, W. M. J. (1997). As formas de significação como mediação da consciência: um estudo sobre o movimento da consciência de um grupo de professores. Tese de Doutorado, Pontifícia Universidade Católica de São Paulo, São Paulo.

\section{Sobre a Autora}

Adriana de Fátima Franco (adriffranco@hotmail.com)

Universidade Tuiuti do Paraná

\section{Correspondência}

Rua Antônio Gruba, 239 sob 8

CEP 80820-340 Vista Alegre Curitiba - PR

\section{Agradecimentos}

Pesquisa apoiada pela CAPES
Oliveira, I. M. de. (1994). Preconceito e autoconceito: identidade e interação na sala de aula (Coleção Magistério, Formação e Trabalho Pedagógico). Campinas, SP: Papirus.

Patto, M. H. S. (1996). A produção do fracasso escolar: histórias de submissão e rebeldia. São Paulo: T. A. Queirós.

Petrovski, A. V. (1989). Psicologia. Moscou: Progresso.

Pino, A. (1999). A psicologia concreta de Vigotski: implicações para a Educação. Psicologia da Educação, 7-8, 29-52.

Poli, S. M. (2003). Aceleração da aprendizagem: de quem?. Chapecó, SC: Argos.

Rossetti-Ferreira, M. C., Amorin, K. S., \& Silva, A. P. S. da. (2004). Rede de significações: alguns conceitos básicos. Em M. C. Rossetti-Ferreira, K. de S. Amorim \& A. P. S. Silva (Orgs.), Rede de significações e o estudo do desenvolvimento humano (pp.2333). Porto Alegre: Artmed.

Santos, S. (2003). Relembrando a trajetória de vida: uma forma de alcançar a articulação entre auto-conceito, auto-estima e desempenho docente?. Dissertação de Mestrado, Pontifícia Universidade Católica de São Paulo, São Paulo.

Saviani, D. (1995). Escola e democracia (29a ed.). Campinas, SP: Autores Associados.

Saviani, D. (2004). Perspectiva marxiana do problema subjetividadeintersubjetividade. Em N. Duarte (Org.), Crítica ao fetichismo da individualidade (pp.21-46). Campinas, SP: Autores Associados.

Silva, I. V., Alencar, E. M., \& Gonzáles, L. S. (1986). Autoconceito, rendimento acadêmico e escolha do lugar de sentar entre alunos de nível sócio econômico médio e baixo. Arquivos Brasileiros de Psicologia, 36(1), 89-96.

Sirgado. P. A. (2000). O social e o cultural na obra de Vygotski. Educação e Sociedade, 71, 45-78.

Smolka, A. L. (2004). Sentido e significação: sobre significações e sentido: uma contribuição à proposta de rede de significação. Em M. C. Rossetti-Ferreira, K. de S. Amorim \& A. P. S. Silva (Orgs.), Rede de significações e o estudo do desenvolvimento humano (pp. 35-49). Porto Alegre: Artmed.

Tavares, M. (2002). Auto-estima: o que pensam os professores?. Tese de Doutorado, Pontifícia Universidade Católica de São Paulo, São Paulo.

Vigotsk, L. S. (1987). Pensamento e linguagem. São Paulo: Martins Fontes.

Vigotski, L. S. (1991). La psique, la consciencia, el inconsciente. Em L. S. Vigotski, Obras Escogidas (pp. 95-110). Madrid: Centro de Publicaciones del M.E.C. y Visor Distribuciones.

Vigotski, L. S. (1993). Las emociones y su desarrollo en la edad infantil. Em L. S. Vigotski, Obras Escogidas II (pp. 403-22). Madrid: Centro de Publicaciones del M.E.C. y Visor Distribuciones. 